\title{
ARMAZENAMENTO DE SEMENTES E SOMBREAMENTO NA EMERGÊNCIA E CRESCIMENTO INICIAL DAS MUDAS DE Magonia pubescens A. St.-Hil. ${ }^{1}$
}

Tatiane Sanches Jeromini ${ }^{2}$, Silvana de Paula Quintão Scalon ${ }^{3}$, Suzana Targanski Sajovic Perreira ${ }^{2}$, Ricardo Fachinelli² e Homero Scalon Filho ${ }^{4}$

\begin{abstract}
RESUMO - A conservação das sementes e a quantidade de luz são fatores importantes para uma boa germinação e produção de mudas de qualidade. Em vista disso, este trabalho avaliou o efeito da embalagem das sementes durante o armazenamento e de diferentes níveis de luz na emergência e crescimento inicial das mudas de timbó (Magonia pubescens St. Hil.). Foram realizados dois experimentos. No primeiro, foi analisado o efeito do armazenamento das sementes em três tipos de embalagem (papel-alumínio, papel e saco plástico de polietileno de baixa densidade) e a duas temperaturas $\left(10\right.$ e $\left.25^{\circ} \mathrm{C}\right)$, durante três épocas de armazenamento (30, 60 e 90 dias) e sem armazenamento. No segundo experimento, foi estudado o crescimento inicial das mudas em três níveis de sombreamento (30, 50 e 70\%) e a pleno sol. As sementes de $M$. pubescens germinam melhor quando não armazenadas, com médias de $97 \%$, em comparação com aquelas com $69 \%$ após 90 dias de armazenamento. Caso necessário, o armazenamento deve ser realizado em saco plástico na temperatura de $25^{\circ} \mathrm{C}$, por até 90 dias. As mudas apresentaram maior emergência e qualidade quando a semeadura e o crescimento foram realizados sob sombreamento de $50 \%$.
\end{abstract}

Palavras-chave: Conservação de sementes; Crescimento inicial; Cerrado.

\section{SEED STORAGE AND SHADING IN EMERGENCY AND INITIAL GROWTH OF SEEDLINGS Magonia pubescens A. St.-Hil.}

\begin{abstract}
The conservation of seeds, as well as the amount of light, are important factors for good germination and seedling production quality. In the present study the effect of storage and different levels of light on the emergence and initial growth of seedlings of (Magonia pubescens St. Hil. was evaluated. Two experiments were conducted. In the first one, the storage was done in three packaging types (aluminum foil, paper and plastic bag low density polyethylene) and under two temperatures (10 and $\left.25{ }^{\circ} \mathrm{C}\right)$ for three periods of storage (30, 60 and 90 days) or without storage. In the second experiment the initial growth of seedlings was studied in four shading levels (30, 50 and 70\%) and full sun. The seeds of M. pubescens germinate best when they were not stored, with averages of $97 \%$ compared to $69 \%$ after 90 days of storage. If necessary, the storage must be carried in a plastic bag at $25^{\circ} \mathrm{C}$ for 90 days. The seedlings had higher emergence and quality when sowing and growth were performed under $50 \%$ of shading.
\end{abstract}

Keywords: Packaging; Temperature; Cerrado.

\footnotetext{
${ }^{1}$ Recebido em 04.09.2013 aceito para publicação em 25.03.2015.

${ }^{2}$ Universidade Federal da Grande Dourados, Graduandos em Agronomia, Dourados, MS - Brasil.E-mail: <tati jeromini@hotmail.com>.

${ }_{3}^{3}$ Universidade Federal da Grande Dourados, Faculdade de Ciências Agrárias, Dourados, MS - Brasil. E-mail: <silvanascalon@ufgd.edu.br>.

${ }^{4}$ Universidade Estadual de Mato Grosso do Sul, Curso de Engenharia Ambiental. Dourados, MS - Brasil. E-mail: <homero@uems.br>.
}

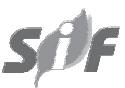

Revista Árvore, Viçosa-MG, v.39, n.4, p.683-690, 2015 http://dx.doi.org/10.1590/0100-67622015000400010 


\section{INTRODUÇÃO}

O timbó (Magonia pubescens St. Hil. - Sapindaceae) é espécie heliófila, pioneira, arbórea, de médio a grande porte, que produz um fruto grande e marrom, com sementes e até $8 \mathrm{~cm}$ de diâmetro, aladas, de cor castanha e taxa de emergência ao redor de $40 \%$ quando não recebem nenhum tratamento. Essas sementes, ricas em saponinas, são usadas na limpeza de úlceras, enquanto o chá de sua casca é empregado no tratamento de feridas e o das raízes, como calmante. A árvore é ornamental, principalmente pela folhagem rendilhada e adapta-se bem a qualquer tipo de solo, podendo ser usada na composição de jardins e praças e, sobretudo na arborização de ruas estreitas, sendo planta pioneira adaptada a terrenos fracos e indicada para plantios de áreas degradadas de preservação permanente (LORENZI, 2002; GUARIM NETO; MORAIS, 2003; GIOTTO et al., 2009; MACEDO et al., 2009). São escassos os trabalhos na literatura sobre a germinação e crescimento de suas mudas.

Uma das técnicas mais efetivas para a conservação da diversidade é o estabelecimento de bancos de germoplasma, ou conservação ex situ. O conhecimento das diferenças da longevidade das sementes é fundamental para o manejo adequado dos bancos de sementes e, no caso das espécies não cultivadas, particularmente importante, considerando a heterogeneidade genética das populações, e qualquer decréscimo significativo na viabilidade resultará na perda de genótipos dos acessos armazenados (PROBERT et al., 2009).

A redução das taxas metabólicas pode prolongar a longevidade das sementes no armazenamento (BERJAK; PAMMENTER, 2003), o que pode ser feito por meio de seu armazenamento com redução da temperatura e utilizando embalagens que minimizem as trocas gasosas e de água com o ambiente. Os tipos de embalagem utilizados no acondicionamento das sementes durante o armazenamento assumem relevante importância na preservação de sua viabilidade e vigor (TORRES, 2005), porque alteram o teor de água das sementes, comprometendo sua conservação e, por consequência, sua viabilidade.

Além do conhecimento sobre armazenamento das sementes nativas, é necessário conhecer métodos de propagação eficientes que possam garantir sua sobrevivência. A produção de mudas a partir de sementes em viveiros é um método comum e viável para propagação de espécies nativas, porém um dos fatores limitantes é o conhecimento da quantidade de luz necessária para a germinação rápida e uniforme das sementes e produção de mudas de qualidade e em quantidade (PACHECO et al., 2006).

Observa-se na literatura que as sementes e mudas das espécies nativas respondem, de maneira variada, à germinação e crescimento inicial, à temperatura, ao tipo de embalagem de armazenamento e à disponibilidade de luz (McLAREN; McDONALD, 2003; AGUIAR et al., 2005; OLIVEIRA et al., 2011; BATISTA et al., 2011; GUEDES et al., 2012; MOTA et al., 2012; RIBEIRO-REIS et al., 2012; SCALON et al., 2012).

Objetivou-se, neste trabalho, avaliar o efeito do armazenamento e sombreamento sobre o comportamento germinativo de sementes e crescimento inicial das mudas de M. pubescens.

\section{MATERIAL E MÉTODOS}

Os frutos de timbó (Magonia pubescens St. Hi1.) foram colhidos de matrizes localizadas a $5 \mathrm{~km}$ da cidade de Amambaí, situada na porção Sul do Estado de Mato Grosso do Sul, com latitude de $23^{\circ} 02^{\prime} 37^{\prime \prime} \mathrm{S}$ e longitude de 5509'10" W (MATO GROSSO DO SUL, 1990).

No Laboratório de Fisiologia Vegetal da Universidade Federal da Grande Dourados (UFGD), em Dourados, MS, após a secagem e deiscência natural, os frutos foram processados e as sementes, extraídas e selecionadas, eliminando-se aquelas de tamanho desuniforme e com sinais de danos físicos.

\subsection{Armazenamento das sementes}

As sementes foram armazenadas em papel-alumínio, papel sulfite e saco plástico de polietileno de baixa densidade e nas temperaturas de 10 e $25^{\circ} \mathrm{C}$, durante 30, 60 e 90 dias, e um controle não foi armazenado. Antes e depois de cada período de armazenamento, avaliou-se o teor de água das sementes.

Antes da semeadura, as sementes foram deixadas de molho em água durante 24 h (MACEDO et al., 2009) e colocadas para germinar em canteiros contendo a mistura solo + areia na proporção de 1:1 (v:v), a uma profundidade de $1 \mathrm{~cm}$, sob telado a $50 \%$ de sombreamento.

Para determinações do teor de água, as sementes foram submetidas ao teste de umidade pelo método da estufa $\left(105^{\circ} \mathrm{C} \pm 3{ }^{\circ} \mathrm{C}\right.$, por $\left.24 \mathrm{~h}\right)$ (BRASIL, 2009). 
O solo utilizado para a semeadura foi classificado como Latossolo-Vermelho distroférrico, de textura argilosa (EMBRAPA, 2006). A irrigação foi realizada de forma a manter $70 \%$ da capacidade de campo.

Foram avaliadas as seguintes características: índice de velocidade de emergência da parte aérea (IVE), empregando-se a fórmula de Maguire (1962), citado por Gusmão et al. (2008), e aos 40 dias após a emergência, a porcentagem de emergência da parte aérea (\%) e o comprimento de parte aérea (CPA), expresso em $\mathrm{cm}$, medida com régua milimétrica, a partir do coleto até a gema apical.

O delineamento estatístico adotado foi inteiramente casualizado em esquema de parcela subsubdividida, em que a parcela foi cada uma das temperaturas, a subparcela de cada embalagem e a subsubparcela de cada época, com quatro repetições de 25 sementes cada. O armazenamento teve duração de até 90 dias. Os resultados foram submetidos à análise de variância; as médias de temperatura de armazenamento e embalagem, comparadas pelo teste de Tukey; e as médias de tempo e a interação entre os tratamentos com o tempo, por análise de regressão, ambas a $5 \%$ de probabilidade. As análises foram realizadas utilizando o programa computacional SISVAR (FERREIRA, 2000).

\subsection{Emergência e crescimento inicial das mudas sob sombreamento}

As sementes foram semeadas em substrato solo + areia, na proporção de 1:1 (v:v), em saco plástico de $3 \mathrm{~L}$, a uma profundidade de $1 \mathrm{~cm}$. As embalagens com as sementes foram mantidas em pleno sol e em casa de vegetação sob telado com redução da luminosidade de 30, 50 e 70\%. A irrigação foi realizada de forma a manter $70 \%$ da capacidade de campo. Aos 40 dias após a emergência, foram medidas as seguintes características:

Emergência: porcentagem (\%) de emergência da parte aérea, tempo médio de emergência (TME) e índice de velocidade de emergência (IVE), empregando a fórmula de Maguire (1962 citado por GUSMÃO et al., 2008).

Crescimento inicial das mudas: teor de clorofila no segundo par de folhas completamente expandidas, utilizando o equipamento medidor de índice de clorofila SPAD 502; número de folhas; diâmetro do coleto $(\mathrm{cm})$, com o auxílio de paquímetro digital; comprimento da parte aérea $(\mathrm{cm})$ e comprimento de raiz $(\mathrm{cm})$, medidos com régua milimetrada; massa de matéria fresca utilizando balança de precisão $(0,001 \mathrm{~g})$ e massa de matéria seca de parte aérea e de raiz, utilizando estufa de secagem com circulação forçada de ar a $60^{\circ} \mathrm{C}$ até a obtenção de peso constante; pesagem em balança de precisão; e índice de qualidade de Dickson (IQD), obtido pela fórmula IQD = massa de matéria seca total/ relação altura/diâmetro do coleto + relação massa de matéria seca da parte aérea/massa de matéria seca da raiz (DICKSON et al., 1960).

O delineamento estatístico adotado foi inteiramente casualizado com quatro repetições de 25 sementes por tratamento para avaliar a emergência e quatro repetições de 10 mudas para avaliar o crescimento. Os resultados foram submetidos à análise de variância e as médias, comparadas pelo teste de Tukey a $5 \%$ de probabilidade; para avaliar o efeito do tempo de armazenamento, as médias foram ajustadas por equações de regressão, sendo considerados somente os ajustes linear e quadrático. As análises foram realizadas utilizando o programa computacional SISVAR (FERREIRA, 2000).

\section{RESULTADOS}

\subsection{Armazenamento das sementes}

O teor de umidade das sementes de $M$. pubescens foi de $9 \%$ e não variou ao longo do armazenamento em nenhuma das embalagens. Ao avaliar a emergência das sementes em função da duração do armazenamento, observou-se que a porcentagem de emergência foi minimamente reduzida com o passar dos dias (Figura 1a), porém a emergência não variou significativamente em razão das temperaturas e dos tipos de embalagens de armazenamento, mantendo-se com média de $71 \%$. Isso mostra que o timbó é tolerante ao armazenamento até os 90 dias.

De modo geral, as sementes armazenadas em temperatura ambiente $\left(25^{\circ} \mathrm{C}\right)$ germinaram com maior velocidade e de forma linear, e a velocidade diminuiu conforme o tempo de armazenamento, enquanto as sementes armazenadas na temperatura de $10{ }^{\circ} \mathrm{C}$ apresentaram menor IVE, com valor mínimo $(0,582)$ observado aos 72 dias de armazenagem (Figura 1b).

A emergência foi mais rápida logo após o processamento e antes do armazenamento (Figura 1c), e a embalagem que se mostrou melhor para armazenagem 
a)

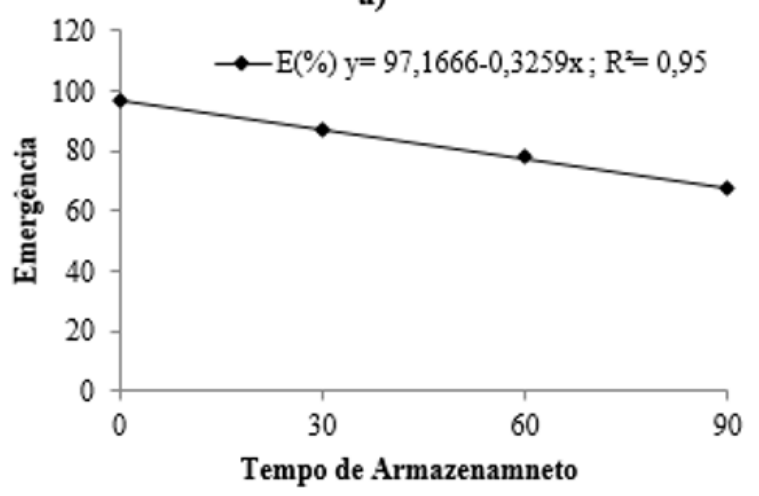

b)

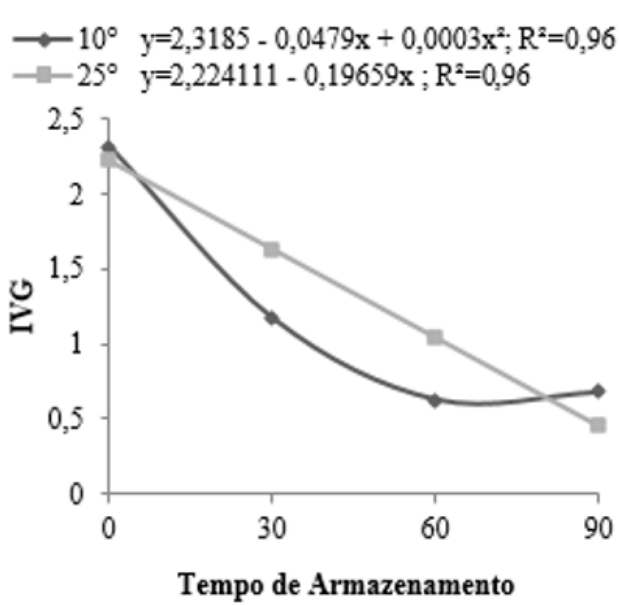

c)

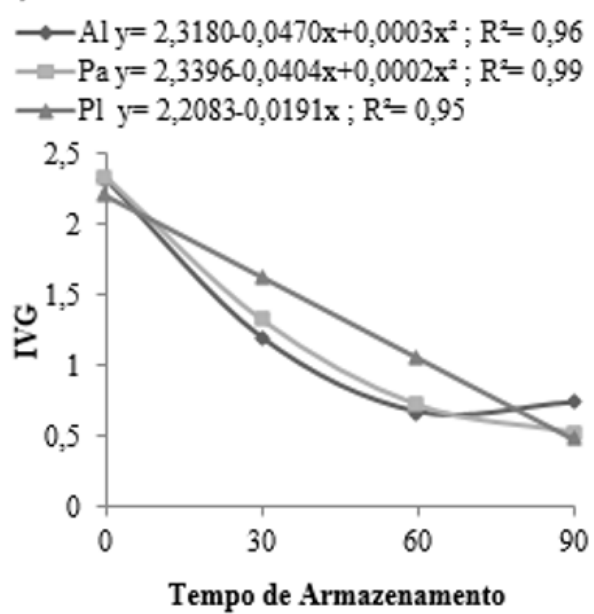

Figura1 - Porcentagem de emergência (\%) (a), índice de velocidade de emergência (IVE) de timbó (Magonia pubescens), em função do tempo e da temperatura de armazenamento (b) e do tipo de embalagem (c).

Figure 1 - Percentage of emergence (\%) (a), the speed of emergence index (SEI) of timbó (Magonia pubescens) in function of storage time and temperature (b) and packaging (c).

foi a de plástico, que proporciona, em média, maior IVE (Figura 1c). Assim, as sementes germinam melhor quando não armazenadas, mas, caso necessário, o armazenamento deve ser realizado em saco plástico e na temperatura de $25^{\circ} \mathrm{C}$, por até 90 dias.

Não houve diferença significativa do comprimento da parte aérea entre as embalagens nas mesmas temperaturas de armazenamento das sementes. Todavia, apenas quando se compararam as duas temperaturas para a embalagem de plástico, houve maior comprimento quando as sementes de $M$. pubescens foram armazenadas em temperatura ambiente $\left(25^{\circ} \mathrm{C}\right)$ (Figura 2).

\section{Emergência e crescimento inicial das mudas sob sombreamento}

Não foi observada influência significativa dos níveis de sombreamento para porcentagem de emergência (71\%), índice de velocidade de emergência $(0,53)$, comprimento de parte aérea $(13,50 \mathrm{~cm})$, diâmetro do coleto $(3,58 \mathrm{~mm})$, comprimento de raiz $(23,41 \mathrm{~cm})$, número de folhas $(23,16)$ e massa fresca da parte aérea $(5,381 \mathrm{~g})$ e da raiz $(2,152 \mathrm{~g})$. As demais características variaram em função do sombreamento, não apresentando padrão de resposta.

O tempo médio de emergência foi menor no sombreamento de $70 \%$, a massa de matéria seca 
da parte aérea e da raiz foi maior a pleno sol e, sob 30 e $50 \%$ de sombreamento, o teor de clorofila foi maior nas folhas das mudas crescidas sob $70 \%$ de sombreamento e o índice de qualidade de Dickson, nas plantas a pleno sol e sob $50 \%$ de sombra (Tabela 1).

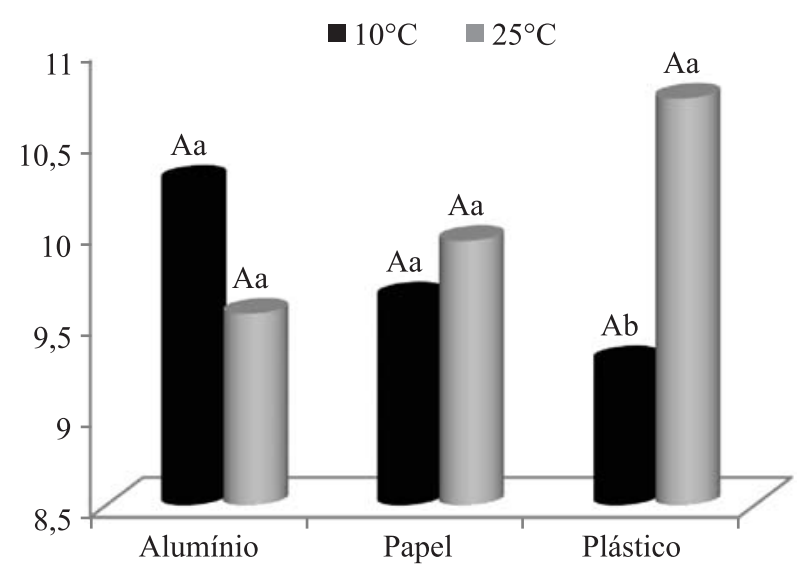

Figura 2 - Comprimento de parte aérea (CPA) de mudas de Timbó, em função a diferentes temperaturas e embalagens. Médias seguidas de mesma letra maiúscula comparam diferentes embalagens na mesma temperatura e médias seguidas de mesma letra minúsculas comparam diferentes temperaturas na mesma embalagem pelo teste de Tukey e F respectivamente ambos a $5 \%$.

Figure 2 - Length of shoot (CPA) seedlings Timbo, due to different temperatures and packaging. Means followed by the same uppercase compare different packages at the same temperature and means followed by the same letter lowercase compare different temperatures in the same package by Tukey test and F respectively both 5\%.

\section{DISCUSSÃO}

As médias observadas de emergência das sementes de Magonia pubescens St. Hill., mesmo após cada período de armazenamento, encontravam-se acima dos valores observados por Macedo et al. (2009), que compararam a emergência das sementes recémprocessadas sem tratamento $(41 \%)$ e com tratamentos pré-germinativos e, com a imersão em água por $24 \mathrm{~h}$, esses autores encontraram a maior emergência (80\%). Tais resultados sugerem que, mesmo com a redução da emergência, as sementes ainda mantêm alto potencial de germinação.

A redução da emergência das sementes de $M$. pubecens com o armazenamento sugere a ocorrência de início de perda do vigor da semente com o passar dos dias de armazenamento, principalmente sob temperaturas mais baixas. Isso porque essa temperatura de armazenamento pode ter causado alterações no metabolismo e integridade do embrião, reduzindo a atividade respiratória em nível prejudicial ao processo.

Oliveira et al. (2011), Batista et al. (2011), Guedes et al. (2012), Ribeiro-Reis et al. (2012) e Scalon et al. (2012) sugeriram que as condições adequadas de armazenamento possibilitam a manutenção da viabilidade e vigor das sementes por um período mais longo do que o obtido em condições naturais. Assim, a constituição da embalagem, a temperatura e o ambiente de armazenamento podem ser considerados os fatores mais importantes para a manutenção da qualidade fisiológica das sementes; entretanto, a condição ideal de armazenamento vai depender da espécie.

Resultados semelhantes aos observados em $M$. pubescens também o foram em outras espécies em

Tabela 1 - Tempo médio de emergência (TME), teor de clorofila, massa seca da parte aérea (MSPA), massa seca de raiz (MSR) e índice de qualidade de Dickson (IQD) de mudas de Timbó aos 40 dias de idade em função a diferentes níveis de sombreamento.

Table 1 - Average time emergency (TME), chlorophyll content, shoot dry matter (SDM), root dry weight (MSR) and Dickson quality index (IQD) seedlings Timbo at 40 days of age function at different levels of shading.

\begin{tabular}{ccccc}
\hline SOBREAMENTO & TME & Clorofila & MSPA & MSR \\
\hline Pleno sol & $26,81 \mathrm{~b}$ & $28,4 \mathrm{~b}$ & $0,96 \mathrm{ab}$ & $0,96 \mathrm{ab}$ \\
$30 \%$ & $28,91 \mathrm{~b}$ & $32,26 \mathrm{~b}$ & $0,57 \mathrm{ab}$ & $0,79 \mathrm{ab}$ \\
$50 \%$ & $26,48 \mathrm{ab}$ & $33,4 \mathrm{ab}$ & $1,17 \mathrm{a}$ & $0,47 \mathrm{~b}$ \\
$70 \%$ & $21,81 \mathrm{a}$ & $40,86^{\mathrm{a}}$ & $0,37 \mathrm{~b}$ & $0,98^{\mathrm{a}}$ \\
\hline
\end{tabular}

Médias seguidas pela mesma letra maiúscula não diferem significativamente entre si, pelo teste de Tukey a 5\% de significância. Means followed by the same capital letter do not differ significantly by Tukey test at 5\% significance. 
razão, provavelmente, do fato de essa condição de armazenamento possibilitar a manutenção da umidade e conservação das sementes. Sementes de Gliricidia sepium (Jacq.) Steud (RIBEIRO-REIS et al., 2012), Myracrodruon urundeuva Fr. All. (GUEDES et al., 2012), Caesalpinia pyramidalis Tul. (OLIVEIRA et al., 2011) e Cedrela odorata L. (BATISTA et al., 2011) também mantiveram maior qualidade fisiológica quando armazenadas em saco plástico, e as sementes de $M$. urundeuva apresentaram redução na emergência, índice de velocidade de emergência e comprimento de plantas em todos os ambientes e embalagens, sendo o comprimento de plântulas o mais afetado, porém as temperaturas variaram entre as espécies. Scalon et al. (2012) observaram em Croton urucurana L. que a emergência também foi maior e mais rápida antes do armazenamento, entretanto se manteve maior (acima de 50\%) quando o armazenamento ocorreu sob refrigeração $\left(10^{\circ} \mathrm{C}\right)$, em comparação com a temperatura ambiente $\left(25^{\circ} \mathrm{C}\right.$ ) (abaixo de $50 \%$ ).

Delouche et al. (1973) comentaram que a deterioração é inevitável e irreversível, sendo a velocidade das transformações degenerativas dependente das condições nas quais a semente foi exposta antes e depois da colheita. Entretanto, com as sementes de M. pubescens, essa deterioração não aconteceu até os 90 dias de armazenamento.

Em relação ao sombreamento, outras espécies apresentaram resultados semelhantes aos observados em M. pubescens. Verificou-se que a germinação das sementes de Dipteryx alata Vog. (MOTA et al., 2012) e Caesalpinia echinata Lam (AGUIAR et al., 2005) não variaram significativamente entre os níveis de sombreamento e a pleno sol a que foram submetidas. O comportamento das sementes dessas espécies nem sempre está associado ao grupo sucessional a que pertencem, e Aguiar et al. (2005) sugeriram que esse potencial de germinar em qualquer ambiente luminoso seja característica atribuída à plasticidade fenotípica da espécie.

O menor tempo de emergência no maior nível de sombreamento possivelmente possa ter ocorrido, porque o substrato nesse ambiente mais sombreado perde umidade mais lentamente devido à menor temperatura causada pelo sombreamento, levando à menor evaporação (MOTA et al., 2012).

As maiores médias de MSPA, MSR e IQD observadas nas mudas cultivadas sob $50 \%$ de sombreamento e que não variaram significativamente daquelas cultivadas a pleno sol sugeriram que essa condição de luz favoreceu o metabolismo fotossintético ao possibilitar um ambiente de umidade de solo e temperatura que permitiram os estômatos se conservarem abertos por mais tempo, mantendo a produção de fotoassimilados, embora essas características não tenham sido avaliadas. Entretanto, esse comportamento não se aplica ao ambiente mais sombreado de $70 \%$, pois nessa condição a luz disponível certamente não foi suficiente para manter o metabolismo e sustentar as exigências das plantas, o que levou a menores valores de IQD.

Esses resultados comprovam informações observadas na revisão de Macedo et al. (2009) a respeito de essa espécie ser heliófita e pioneira; logo, necessita de mais luminosidade.

A maior quantidade de clorofila nos maiores sombreamentos é uma resposta importante para maximizar a captação dos raios luminosos. Mudas de Bombacopsis glabra (Pasq.) A. Robyns (SCALON et al., 2003), Caesalpinia pyramidalis Tul. (DANTAS et al., 2009) e M. urundeuva Allemão (SCALON et al., 2013) apresentaram maior crescimento a pleno sol, entretanto maior índice de clorofila sob sombreamento. Scalon et al. (2003; 2013) observaram, em sua revisão, que o aumento dos teores de clorofila nas folhas aumentou também a capacidade de absorção de luz, de diferentes comprimentos de onda nos picos da fotossíntese, tal como a luz na faixa do azul, presente em grande quantidade em locais sombreados. O aumento da proporção de clorofila b é característica importante de ambientes sombreados, porque ela capta energia de outros comprimentos de onda e a transfere para a clorofila a, que efetivamente atua nas reações fotoquímicas da fotossíntese e representa um mecanismo de adaptação à condição de menor intensidade luminosa.

De maneira semelhante ao observado nesta pesquisa, Giotto et al. (2009), testando quatro matrizes de Magonia pubescens em semeadura direta em casa de vegetação ( $50 \%$ de sombreamento), semeadura direta a pleno sol e em rolo de papel em laboratório com análises em quatro épocas após a emergência, observou, de forma geral, melhores resultados na casa de vegetação a $50 \%$ de sombreamento, assim como maior diâmetro de coleto e altura das plantas em todas as avaliações, mostrando crescimento inicial satisfatório. 


\section{CONCLUSÕES}

As sementes de timbó (Magonia pubescens St. Hil.) germinaram melhor quando não armazenadas. As mudas apresentaram menor tempo médio de emergência e maior qualidade quando a semeadura e o crescimento foram realizados sob sombreamento de $50 \%$.

\section{REFERÊNCIAS}

AGUIAR, F. F .A. ; KANASHIRO, S.; TAVARES, A. R.; PINTO, M. M.; STANCATO, G. C.; AGUIAR, J.; NASCIMENTO, T. D. R. Germinação de sementes e formação de mudas de Caesalpinia echinata Lam. (Pau - Brasil): efeito de sombreamento. Revista Árvore, v.29, n.6, p.871-875, 2005.

BATISTA, I. M. P.; FIGUEIREDO, A. F.; SILVA, A. M.; SILVA, T. A. F. Efeito de embalagens, ambientes e períodos de armazenamento na germinação e no vigor das sementes de cedro (Cedrela odorata) em Manaus - AM. Revista Floresta, v.41, n.4, p.809-818, 2011.

BERJAK, P.; PAMMENTER, N.W. Understanding and handling desiccation-sensitive seeds. In: SMITH, R.D.; DICKIE, J.B.; LININGTON, S.H.; PRITCHARD, H.W.; PROBERT, R.J. (Ed.) Seed conservation - Turning science into practice. Kew: Royal Botanic Gardens, 2003. p.417-430.

BRASIL. Ministério da Agricultura e da Reforma Agrária. Regras para análises de sementes. Brasília-DF: SNDA/DNDV/CLAV, 2009. 365p.

DANTAS, B. F.; LOPES, A. P.; SILVA, F. F. S.; LÚCIO, A. A.; BATISTA, P. F.; PIRES, M. M. M. L.; ARAGÃO, C. A. Taxas de crescimento de mudas de catingueira submetidas a diferentes substratos e sombreamentos. Revista Árvore, v.33, n.3, p.413-423, 2009

DELOUCHE, J.C.; BASKIN, C.C.Accelerated aging techniques for predicting the relative storability of seed lots. Seed Science and Technology, v.52, n.1, p.427, 1973.

DICKSON, A.; LEAF, A.L.; HOSNER, J.F. Quality appraisal of white spruce and white pine seedling stock in nurseries. Forest Chronicle, v.36, n.1, p.10-13, 1960 .
EMPRESA BRASILEIRADEPESQUISA

AGROPECUÁRIA - EMBRAPA. Centro Nacional de Pesquisa de Solos. Sistema brasileiro de classificação de solos. 2.ed. Rio de Janeiro: 2006.306p.

FERREIRA, D.F. Manual do sistema Sisvar para análises estatísticas. Lavras: Universidade Federal de Lavras, 2000. 63p.

GUEDES, R. S.; ALVES, E. U. ; BRUNO, R. L. A.; GONÇALVES, E. P.; COSTA, E.G.; MEDEIROS, M. $\mathrm{S}$. Armazenamento de sementes de Myracrodruon urundeuva Fr. All. em diferentes embalagens e ambientes. Revista Brasileira de Plantas Medicinais, v.14, n.1, p.68-75, 2012.

GIOTTO,A.C.; MIRANDA, F.S.; MUNHOZ, C.B.R. Aspectos da germinação e crescimento de mudas de Magonia pubescens A. St. Hill. Cerne, v.15, n.1, p.49-57, 2009.

GUARIM NETO, G.; MORAIS, R.G. Recursos medicinais de espécies do Cerrado de Mato Grosso: um estudo bibliográfico. Acta Botanica Brasilica, v. 17, n.4, p.561-584, 2003.

GUSMÃO, E.; VIEIRA, F.A.; FONSECA JÚNIOR, E.M. Biometria de frutos e endocarpos de murici (Byrsonima verbascifolia Rich. ex A. Juss.). Cerne, v.12, n.1, p.84-91, 2006.

LORENZI, H.E. Árvores brasileiras: manual de identificação e cultivo de plantas arbóreas nativas do Brasil. 4.ed. Nova Odessa: Instituto Plantarum, 2002. v.1.384p.

MACEDO, M. C.; SCALON, S. P. Q.; SARI, A. P.; SCALON FILHO, H.; ROSA, Y. B. C. J.; ROBAINA, A. D. Biometria de frutos e sementes e germinação de Magonia pubescens St. Hil (Sapindaceae). Revista Brasileira de Sementes, v.31, n.2, p.202-211, 2009.

MATO GROSSO DO SUL. Secretaria de Planejamento e Coordenação Geral. Atlas multirreferencial. 1990 . $28 \mathrm{p}$.

McLAREN, K.P.; McDONALD, M.A. The effects of moisture and shade on seed germination and seedling survival in a tropical dry forest in Jamaica. Forest Ecology and Management, v.183, n.1, p.61-75, 2003.

Revista Árvore, Viçosa-MG, v.39, n.4, p.683-690, 2015 
MOTA, L.H.S.; SCALON, S.P.Q.; HEINZ, R.

Sombreamento na emergência de plântulas e no crescimento inicial de Dipteryx alata Vog.

Ciência Florestal, v.22, n.3, p.423-431, 2012.

OLIVEIRA, L. M.; BRUNO, R. L. A.; SILVA K. R. G.; ALVES, E. U.; SILVA, G. Z. A.P. A. Qualidade fisiológica de sementes de Caesalpinia pyramidalis Tul. durante o armazenamento. Revista Brasileira de Sementes, v.33, n.2, p.289- 298, 2011.

PACHECO, M. V.; MATOS, V. P.; FERREIRA, R. L. C.; FELICIANO, A. L. P.; PINTO, K. M. S.

Efeito de temperatura e substrato na germinação de sementes de Myracrodruon urundeuva Fr. All. (Anacardiaceae). Revista Árvore, v.30, n.3, p.359-367, 2006.

PROBERT, R.J.; DAWS, M.I.; HAY, F.R.

Ecological correlates of ex situ seed longevity: a comparative study on 195 species. Annals of Botany, v. 14, n.1, p.1-13, 2009.

REIS, R. C. R.; PELACANI, C. R.; ANTUNES, C. G. C.; DANTAS, B. F.; CASTRO, R. D.

Physiological quality of Gliricidia sepium (Jacq.)

Steud. (Leguminosae - Papilionoideae) seeds subjected to different storage conditions.

Revista Árvore, v.36, n.2, p.229-235, 2012.

SCALON, S.P.Q.; MOTA, L.H.S.; MUSSURY, R.M. Osmotic conditioning and shading on the germination and on the initial growth of Myracrodruon urundeuva Allemão seedlings. Annais da Academia Brasileira de Ciências, v. 85, n.2, p.799-812, 2013.

SCALON, S. P. Q.; MUSSURY, R. M.; RIGONI, M. R.; SCALON FILHO, H. Crescimento inicial de mudas de Bombacopsis glabra (Pasq.) A. Robyns sob condição de sombreamento. Revista Árvore, v.27, n.6, p.753-758, 2003.

SCALON, S.P.Q.; MUSSURY, R.M.; LIMA, A.A. Germination of Croton urucurana L. seeds exposed to different storage temperatures and pre-germinative treatments. Anais da Academia Brasileira de Ciências, v. 84, n.1, p.191-200, 2012.

TORRES, S.B. Qualidade de sementes de melancia armazenadas em diferentes embalagens e ambientes. Revista Ciência Agronômica, v.36, n.2, p.163-168, 2005. 